\title{
Three Piece Wheel Rim Weight Reduction by Finite Element Analysis
}

Nilesh Kumar Popatlal Kankariya ${ }^{1}$

ME (Design) - Mechanical Engineering Department JSPM's -R.S.College of Engineering, Pune, Maharashtra

\author{
Prof. Shailesh S Pimple ${ }^{2}$ \\ ME (Design) - Mechanical Engineering Department \\ JSPM's -R.S.College of Engineering, Pune, Maharashtra
}

\begin{abstract}
All vehicle manufacturing companies are emphasizing to reduce vehicle weight to improve fuel economy with minimum product cost. Vehicle kerb weight can be reduced by introducing innovative manufacturing processes, vehicle system part design optimization. Optimizing the weight of wheel is more effective than any other components of vehicle. Vehicle tyre takes overall vehicle load which gives dampening effect.

The objective of this project is to optimize three piece wheel rim design by introducing variable wheel wall thickness to reduce weight and cost of the wheel rim without affecting its key functions and its fatigue life. Wheel rim disc with variable thickness will be design in PRO-E and structural stress analysis on modified design by using Finite Element Method with given boundary condition.
\end{abstract}

Keywords - Wheel rim; Wheel rim disc; Variable thickness; ProE design; FEM.

\section{INTRODUCTION}

In any vehicle wheel is a key component which holds whole mass as well as keep the contact between the car and the road. Wheel should be powerful and can get through the roughest of terrains. Truck can't perform its functions without correct functioning of the wheels. Vehicle wheel along with its suspension sustains static and dynamic loads in vehicle running operations.

Vehicle moves on the most vital elements that is wheels so it must be designed carefully. Vehicle wheels will have to function in various road and field terrains and also various hazardous atmosphere too. Wheels are designed in such a way to meet safety and basic engineering criteria with optimum performance. The wheel should sustain shocks, vibrations from various terrain and mass of the all types loads; wheel mass should be lighter but highly durable. Wheel rims size, weight, material, design affect the braking performance of a vehicle.

A typical three piece wheel rim is as shown below,

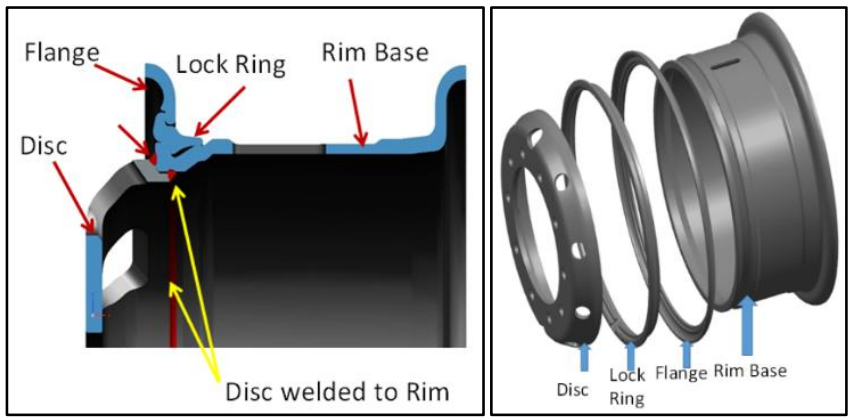

Fig.1 Three piece wheel rim Nomenclature
Among the wheels the wheel rim is most critical and vehicle safety and regulatory components. Wheel rim holds vehicle tires at the outer edge. Which makes wheel outer design is circular and wheel on which the inside edge of the tire is mounted of automobiles. Wheel contribution in vehicle performance has vital importance on roads. Wheel rim is in three pieces rim, flange \& lock ring. This type of wheel rim is newly introduced to overcome demerits of two piece wheel rim. Three piece wheel rim is easy to handle in field \& also address safety concern of end customer.

In the last few decades rim has a substantial enhancement in there design and its verification procedures.

In this perspective expecting design with significant wheel mass reduction without compromise in its function and performance. Lighter wheel rim without compromising its function, strength, life is a major task for wheel rim producers.

The above mentioned wheel rim weight can be reduced by recognizing the various stress regions and accordingly change wheel rim design. Rim disc material can be reduced wherever there is lower stress region and has low vehicle load effect.

\section{PROBLEM DEFINITION /NEED FOR PROJECT}

At present vehicle has recommended wheel rim size has higher weight, cost which need to be analyzed under finite element analysis. Analysis to determine the material removal area from current design within given condition. There is significant advantages for lighter mass vehicle wheels and its sub-systems like improvement in mileage, raw material yield, simplified manufacturing process, less cost of ownership which in turn minimizes overall cost.

\section{LITERATURE REVIEW}

\section{S. Chaitanya, B.V. Ramana Murty (1)}

Mass optimization of auto wheel paper presented by $S$. Chaitanya and B.V. Ramana Murty. The current opportunity of analysis is raised for the improvement of auto wheel rim to carry out weight optimization. Considering wheel stresses, mass into account PEEK with $30 \%$ carbon reinforced recommended material to replace the aluminium alloy. It was observed that high stresses are near bolt holes but it was less than material yield stress. Compare to aluminium alloy stresses are less in titanium, magnesium alloy. Due to low density of magnesium alloy powder there is huge risk of fire so use of such alloy in the form of dust is unsafe. With alternate proposed $30 \%$ carbon reinforced material for auto wheel rim the stresses are in acceptable range. With this research paper it is determined that PEEK with $30 \%$ carbon reinforced material is best suitable material for auto wheel rim. It also determined that all stresses which are developed in auto wheel rim are well 
within acceptable limit and accordingly weight optimization is achieved.

\section{Sourav Das (2)}

Design and mass optimization of aluminium wheel paper presented by Sourav Das. In this research wheel optimization, wheel assembly and its types divided into two region, scope to change design scheme and no scope to change design scheme. The region where no scope to change design will have standard design. The region where there is opportunity to change design will minimize the weight and improve design of the arms. Design scheme optimized in such way that can sustain various loads with sufficient safety margin with bare minimum material and development cost and if any losses. To withstand various loads and stresses five arm design structure is optimal. It was observed that weaker region or high stress region is around rim flange. Fatigue analysis determines that proposed material can withstand for anticipated product life cycle. By finite element analysis method original mass of rim is decrease by $48 \%$. Modified wheel rim design arm shape and its section simplified for ease of manufacturing and equal stresses distribution.

\section{R. Muthuraj, R. Badrinarayanan, T. Sundararajan} (3)

Improvement in the wheel design using actual loading conditions - Finite element analysis and Experimental Stress analysis comparison paper presented by R. Muthuraj, R. Badrinarayanan, T. Sundararajan. In his paper rim design and comparative stresses are explained and further evaluation of wheel rim durability performance finite element and experimental stress analysis with actual loading conditions explained. In this research paper current design and proposed forged alloy wheel test results compare using experimental stress and finite element analysis. So by this research there are improvement are suggested in wheel design. In FEA analysis all loading conditions are realistic or actual. Conclusion were drawn by comparing finite element analysis and experimental stress analysis.

\section{R. Muthuraj, Dr. T Sundararajan (4)}

In The Forged Hybrid wheel for heavy commercial vehicles paper presented by Muthuraj and Dr. Sundararajan.

Robust design for enhance manufactured goods prime function and its services has defined forged hybrid Wheel towards material mass saving in heavy commercial vehicles approx. $41 \%$ as a component and $18 \%$ gross as wheels assembly. Hybrid Wheel to be used with tube type tires. With use of current tube tire assembly which offer all advantages of aluminium wheels reduces development cost on wheels. Which increases fuel economy by $5 \%$, tyre life increased by $30 \%$ with reduce driver fatigue but only things is forged Hybrid Wheel is costlier than Steel wheel rim.

\section{Haruo Nagatani, Tsuyoshi Niwa (5)}

Topology Optimization of application and its Shape for HubBearing lightening development paper presented by Haruo Nagatani and Tsuyoshi Niwa.

Hub bearing shape and weight optimization analysis performed for lightening weight of cars. Wheel hub bearing profile optimization were done considering the mechanical strength. However, hub bearing rigidity target needs to be set.
Therefore, considering appropriate hub bearing rigidity margin various method of optimization in phases to be done to reduce weight of wheel hub bearing. This way hub bearing technology established and meets the needs of various car manufacturers. Topology optimization mostly suitable for linear problems and does not give precise results for nonlinear analysis. Due to this cause highly precise nonlinear analysis is required to check the outcomes accomplished from topology optimization.

\section{LITERATURE GAP}

After careful review of literature, it is clear that past all weight optimization research work were performed by FEM Analysis either on single piece or two piece wheel rim, optimization of wheel rim using topology optimization, weight optimization by aluminium alloy wheel rim. In none of the literature review papers talks about three piece steel wheel rim optimization with variable wheel disc thickness. There is a clear scope for redesigning wheel disc \& further comparative structural analysis using FEM for weight optimization without affecting key function of intended part and its life.

\section{SOLUTION TO PROBLEM}

Solution to problem is following listed design changes to be incorporated to reduce the three piece wheel rim mass, cost and at same time achieving improved product performance. Recommended changes are variable disc wall thickness for three piece wheel rim to optimize rim mass and cost.

\section{WHAT IS AVAILABLE IN MARKET}

Uniform disc thickness wheel rim as shown in figure

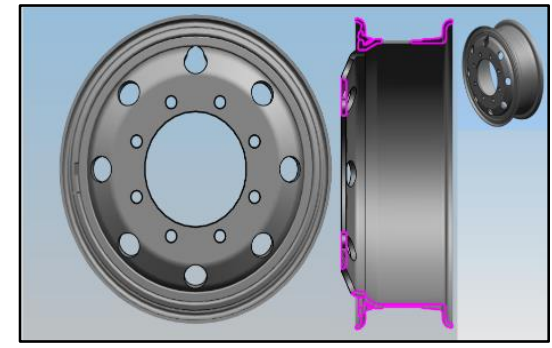

Fig.2 Wheel rim

\section{OBJECTIVES OF PROJECT}

1. Wheel rim disc design optimized with the help of analysis Software ANSYS to reduce thickness and its weight without Compromising its function.

2. Variable thickness disc flow forming manufacturing process Increases its hardening by cold working to get higher yield.

3. Comparative stress analysis for current wheel and proposed design.

\section{SOFTWARE USED:}

1. Pro-E- Creo 5.0 : 3D modelling and 2D drawings.

2. ANSYS : WORK BENCH 14.5 for static structural analysis.

3. MS office : Excel, Word 


\section{Part- I :}

\section{METHODOLOGY}

a) Design and analysis of current and proposed three piece wheel rim for weight and cost optimization.

Development aim of lighter mass three piece wheel rim than the existing wheel rim used for commercial vehicle. Nowadays, optimization techniques are used for weight optimization of components which reduces material and manufacturing cost without affecting its product performance.

i. At present research ILCV 1109 wheel rim is to be studied.

ii. Prepare CAD design of current and modified wheel rim using Pro-E Creo 5.0 software

iii. Perform static structural analysis of both wheel rim with given boundary condition and at various load condition to obtain deformation and von misses Stresses.

iv. Compare FEA results, weight and cost for modified and current wheel rim design.

\section{Part- II :}

Experimental analysis and testing of optimized Three piece wheel rim.

Experimental analysis and testing of wheel rim will be performed to compare existing and proposed design weight, cost and its performance.

\section{FUTURE WORK}

Design of lighter three piece wheel rim for commercial vehicle. Analysis of complete wheel aggregates to reduce its weight and size. Also next we are going to do comparative analysis of the existing and proposed wheel rim disc and save manufacturing cost, product cost \& its weight.

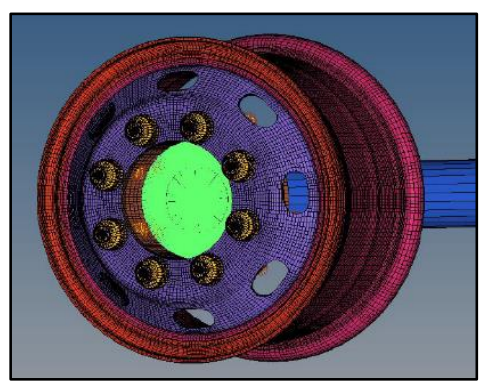

Fig.3 Wheel rim Meshing Model

\section{REFERENCES}

[1] S.Chaitanya and B.V.Ramana Murty "Mass optimization of automobile wheel rim", IJETT, 2015, 26 (3), pp 169-173

[2] Sourav Das "Design and weight optimization of aluminium alloy wheel", IJOSRP, 2014, 4(6), pp1-12

[3] R.Muthuraj, R.Badrinaraynan, T.Sundararajan, "Improvement in the wheel design using actual loading conditions - FEA and ESA comparison", SAE Technical paper series 2011-28- 0106

[4] R. Muthuraj, Dr.T.Sundarajan, "The forged hybrid wheels for heavy commercial vehicles, A robust design for augmented product service and performance", SAE technical paper series 2015-260068.

[5] Haruo Nagatani \& Tsuyoshi Niwa "Application of topology optimization and shape optimization for development of hubbearing lightening”, TN Technical Review 73, 2015, pp14-19

[6] IS 9438

[7] ITTAC 2014 Manual 